\title{
Predição da definição da escolha vocacional a partir de variáveis familiares
}

\section{Predicción de la definición de la elección vocacional a partir de variables familiares Uocacional Choice Definition Prediction from Family Uariables}

\author{
Rodolfo A. M. Ambiel ${ }^{*}$ \\ Adriana S. Ferraz ${ }^{*}$ \\ Natália Simões* \\ Jasiele Silva* \\ Edson Pereira* \\ Universidade São Francisco, Campus de Campinas-SP, Brasil
}

Doi: http://dx.doi.org/10.12804/revistas.urosario.edu.co/apl/a.6193

\section{Resumo}

Na adolescência, a participação da família é considerada como um importante fator no processo de escolha profissional. Objetivou-se a investigação do nível de predição dos estilos parentais, congruência entre pais e filhos e autoeficácia dos filhos em relação à definição da escolha vocacional numa amostra de 140 alunos do ensino médio. As idades variaram de 15 a 18 anos $(M$ $=16.14)$, sendo a maioria do sexo feminino (58\%). Os instrumentos utilizados foram: Questionário Sociodemográfico, Escala de Responsividade e Exigência Parental-EREP, Escala de Congruência entre Pais e Filhos sobre Escolha Profissional-ECPF-EP e Escala de Autoeficácia para Escolha Profissional-EAE-EP. Por meio da análise de regressão hierárquica, os instrumentos foram agrupados em três blocos. O modelo formado a partir do último bloco foi o melhor, sendo que as variáveis responsividade materna, congruência complementar e autoeficácia para busca de informação profissional prática foram os preditores significativos. Sugere-se a continuidade dos estudos.

Palavras-chave: autoeficácia para escolha profissional, relações familiares, estilos parentais, orientação profissional.

* Universidade São Francisco, Campus de Campinas-SP, Brasil

Contacto principal para correspondência editorial: Adriana Ferraz, Universidade São Francisco, Campus de Campinas-SP, Brasil. Correio electrônico: adrianasatico.as@gmail.com

O presente trabalho foi realizado com apoio da Coordenação de Aperfeiçoamento de Pessoal de Nível Superior - Brasil (CAPES) - Código de Financiamento 001.

Para citar este artigo: Ambiel, R., Ferraz, A., Simões, N., Silva, J., \& Pereira, E. (2019). Predição da definição da escolha vocacional a partir de variáveis familiares. Avances en Psicología Latinoamericana, 37(1), 89-101. Doi: http://dx.doi.org/10.12804/ revistas.urosario.edu.co/apl/a.6193 


\section{Resumen}

En la adolescencia, la participación de la familia se considera un factor importante en el proceso de elección profesional. Este estudio investigó el nivel de predicción de los estilos parentales, congruencia entre padres e hijos y autoeficacia de los hijos en relación a la elección profesional en una muestra de 140 alumnos de secundaria. Las edades variaron de 15 a 18 años $(M=16.14)$, siendo la mayoría del sexo femenino (58\%). Los instrumentos utilizados fueron: Cuestionario Sociodemográfico, Escala de Responsabilidad y Exigencia Parental-EREP, Escala de Congruencia entre Padres e Hijos sobre Elección Profesional-ECPF-EP y Escala de Autoeficacia para Elección Profesional-EAE-EP. A través del análisis de regresión jerárquica, los instrumentos se agruparon entres bloques. El modelo formado a partir del último bloque fue el mejor, siendo que las variables responsividad materna, congruencia complementaria y autoeficacia para la búsqueda de información profesional práctica fueron los predictores significativos. Se sugiere la continuidad de los estudios.

Palabras clave: autoeficacia para elección profesional, relaciones familiares, estilos parentales, orientación profesional.

\section{fibstract}

In adolescence, the participation of the family is considered an important factor in the professional choice process. This study aimed to research whether parental styles, parents and children congruence, and children self-efficacy predicted their vocational choice in a sample of 140 high school students. The ages ranged from 15 to 18 years $(M=16.14)$, the majority being females $(58 \%)$. The instruments used were the Sociodemographic Questionnaire, the Parental Responsibility and Requirement Scale-EREP-, the Congruence Scale between Parents and Children on Professional Choice -ECPF-EP- and the Self-Efficacy Scale for Professional Choice-EAE-EP. Through the hierarchical regression analysis, the instruments were grouped into three blocks. The model formed from the last block was the best one, where the variables maternal responsiveness, complementary congruence and self-efficacy to search for practical professional information were the significant predictors. It is suggested that these studies continue. Keywords: Self-efficacy for professional choice, family relationships, parenting styles, professional orientation.

\section{Introdução}

A Orientação Profissional (OP) vem crescendo expressivamente ao longo dos últimos anos por se tratar de um processo que facilita a escolha e construção da trajetória profissional, buscando o desenvolvimento do autoconhecimento e do conhecimento das atividades profissionais/ocupacionais. (Aguiar \& Conceição, 2012; Ambiel, Campos \& Campos, 2017; Mitran \& Pârvu, 2017; Perry \& Shanoon, 2017). Seu principal objetivo é preparar o sujeito para a tomada de decisão profissional e para administração da sua carreira (Aguiar \& Conceição, 2012; Ambiel \& Campos, 2017; Mitran \& Pârvu, 2017).

Em relação ao público-alvo a OP não se restringe a um momento de vida ou público-alvo específico, pois pode ser aplicada em populações variadas como é o caso dos alunos do Ensino Médio (Barros, Noronha \& Ambiel, 2015) e universitários (Oliveira, Santos \& Dias, 2016); de pessoas em situação de vulnerabilidade social (Pinto \& Pinto, 2016), em sujeitos que estão se preparando para a aposentadoria (Pazzim \& Marin, 2016), na inserção de idosos em programas educacionais (Pereira, Couto \& Scorsolini-Comin, 2015), dentre outros contextos. Desta forma, destaca-se a extensa variedade de sujeitos e contextos que podem se beneficiar com a OP. Por conta disto, é necessário que o profissional desta área esteja qualificado para utilizar instrumentos de avaliação e técnicas com respaldo científico e, que seja proativo para colocá-la em prática (Oliveira, Silva, Garcia, Melo-Silva \& Teixeira, 2014). 
A conscientização acerca da importância da OP e a expansão do alcance desse campo são fundamentais, pois, este é um processo significativo ao longo da vida do sujeito (Duarte, 2000). Tratando-se da adolescência, fase abordada no presente estudo, alguns elementos são fundamentais para o andamento desse processo e para a escolha vocacional, como a família, que pode ser considerada como um dos ambientes que mais exercem influência na escolha dos filhos (Almeida \& Pinho, 2008; Simöes, Gamboa \& Paixão, 2016), na formação de identidade do sujeito, no desenvolvimento do autoconceito e da autoeficácia (Ambiel \& Noronha, 2011; Ambiel \& Hernández, 2016; Nepomuceno $\&$ Witter, 2010). A preocupação em abordar os aspectos envolvidos na escolha profissional advém do fato dessa escolha e da profissão em si, apresentarem-se ao adolescente como uma porta de entrada para a sua representação na sociedade. Portanto, aferir as variáveis inerentes à participação da família no momento da escolha profissional dos filhos, como os estilos parentais e a congruência entre pais e filhos, foco deste estudo, se mostra de grande valia tanto para o campo da op quanto para os envolvidos neste processo. Acrescenta-se a esta investigação a autoeficácia para a escolha profissional, em decorrência da sua relevância para o processo de OP, descrita mais adiante (Ambiel \& Hernández, 2016; Lamas, 2017).

Neste sentido Silva, Fuzaro e Pacheco (2016), destacam que a adolescência confere grandes transformações na vida do adolescente, de natureza biológica, psicológica e social. Dentre essas mudanças, aponta-se para o momento da escolha profissional, que se apresenta como um grande desafio para o adolescente, a sua família e a sociedade. Ao apontar para o papel da família, destaca-se que essa é uma importante variável que pode tanto contribuir como prejudicar essa escolha, por influenciar a percepção dos filhos, por meio das atitudes e comportamentos parentais envolvidos nesse processo, como por exemplo, a qualidade da comunicação estabelecida entre pais e filhos (Leung, Hou, Gati
\& Li, 2011; Silva et al., 2016). Portanto, os estilos parentais, um dos construtos avaliados no presente estudo, são abordados por sua relação com a saúde emocional dos adolescentes e que podem interferir positiva ou negativamente durante o processo de escolha profissional (Almeida \& Melo-Silva, 2011; Faria, Weber \& Ton, 2012; Raque-Bogdan, Klingaman, Martin \& Lucas, 2013).

O modelo teórico de estilos parentais adotado neste estudo deriva de Maccoby e Martin (1983). Este modelo se constitui de dois aspectos essenciais nas práticas educativas dos pais, classificados em exigência e responsividade. Os estilos parentais ligados à exigência aludem ao estabelecimento de regras e imposição de limites, com o intuito de controle do comportamento do filho. Por sua vez, os estilos parentais atrelados a responsividade são marcados pela compreensão, apoio emocional e o diálogo entre pais e filhos, os quais corroboram a autonomia e autoafirmação do adolescente (Boudreault-Bouchard et al., 2013, Maccoby \& Martin, 1983; Weber, 2017; Weber, Selig, Bernardi \& Salvador, 2006).

O estudo de Faria et al. (2012) verificou o impacto dos estilos parentais para a saúde emocional dos filhos, em que aspectos ligados à família contribuíram para o estresse de jovens vestibulandos brasileiros. Neste estudo os autores identificaram que a apresentação do estresse se relacionou positivamente com o perfil de pais altamente exigentes, caracterizado por cobranças prolongadas referentes ao desempenho acadêmico e a escolha profissional, pais intrusivos, ausência de respeito à individualidade e a invasão de privacidade. Em contrapartida, o comportamento de pais com altos níveis de responsividade, expresso por apoio emocional e incentivo à autonomia dos filhos associou-se negativamente com o estresse.

Por sua vez, Alvarenga, Magalhães \& Teixeira (2012) aferiram as associações entre a responsividade e exigência dos pais para a indecisão vocacional de 99 estudantes do $3^{\circ}$ ano do Ensino Médio, com idades entre 16 a 22 anos. Os autores 
deste estudo averiguaram que tanto a responsividade paterna quanto materna se correlacionaram negativamente com a indecisão profissional e na análise de regressão a responsividade explicou $2.2 \%$ da variância de indecisão profissional $(\beta=-0.16 ; p=0.02)$, sugerindo que estes aspectos dos estilos parentais auxiliam na escolha profissional dos filhos, visto que quanto maior a responsividade dos pais menor a indecisão dos filhos.

Como mencionado, além dos estilos parentais, a congruência entre pais e filhos sobre a escolha profissional também foi verificada na presente pesquisa. A escolha desse construto apoia-se em Sawitri, Creed \& Zimmer-Gembeck (2012) e Sawitri \& Creed (2015) que asseveram que a percepção da congruência com seus pais suscitam o encorajamento dos filhos no envolvimento de atividades que estimulam a exploração de uma carreira. Esta percepção repercute positivamente no processo de escolha profissional por torná-los mais conscientes em relação à tomada de decisão, bem como promover a sensação de satisfação com a sua escolha.

O conceito de congruência entre pais e filhos sobre a escolha profissional provém do modelo teórico proposto por Kristof (1996) aplicado inicialmente na área organizacional com o objetivo de adaptar os sujeitos nesse contexto (ajustamento). Nessa teoria, a congruência se subdivide em aspectos complementares e suplementares. A partir dos estudos de Sawitri et al. (2012) com esse modelo em uma amostra de adolescentes indonésios ( $N=1062)$, verificou-se que os filhos que classificam a congruência dos pais como complementar os percebe como provedores de suas necessidades em termos de estabelecimento de metas, planejamento e exploração profissional, bem como sentem que seus pais demonstram satisfação sobre o seu progresso em relação a escolha profissional propriamente dita. No que diz respeito à percepção dos filhos sobre pais classificados com a congruência suplementar, constatou-se que os adolescentes acreditavam ter ideias parecidas em relação aos interesses, valores, planos e objetivos relativos à escolha profissional. Desse modo, a orientação pela congruência complementar sugere que os filhos tendem a se sentirem mais encorajados a participar de eventos que interligam a escolha profissional e a aspiração de uma carreira a ser seguida. Por sua vez, a presença da congruência suplementar, remete as semelhanças existentes dos interesses, valores, planos e objetivos profissionais entre pais e filhos. Destaca-se que em comparação aos estilos parentais, estudos com a proposta de avaliar a congruência entre pais e filhos para escolha profissional são considerados inéditos em contexto nacional.

O último construto avaliado na presente pesquisa se refere à autoeficácia para escolha profissional. Proveniente da perspectiva da teoria social cognitiva de desenvolvimento de carreira, a autoeficácia para escolha profissional atua no sujeito em processo de OP em relação à forma como esse se percebe capaz para se organizar e executar determinadas ações a partir do reconhecimento de suas habilidades, bem como de sua capacidade para adquiri-las (Bandura, 1997; Hackett \& Betz, 1981; Lent \& Brown, 2006). Nesse sentido, a autoeficácia se integra aos interesses, os objetivos e ações envolvidas na escolha, até atingir o desempenho e a realização, aspectos que se relacionam com as expectativas de resultados na escolha profissional (Lent, Brown \& Hackett, 1994).

No tocante aos estudos envolvendo a autoeficácia para escolha profissional em contexto nacional, aponta-se para a análise da produção científica de artigos, teses e dissertações sobre a autoeficácia no âmbito do desenvolvimento de carreira realizado por Prisco, Martins \& Nunes (2013). Esse levantamento indicou o número escasso de estudos em âmbito nacional, apesar de a literatura reportar a sua importância para a área da OP. Diante dessa limitação, as autoras destacaram a necessidade de desenvolver estudos com o intuito de investigar a autoeficácia para a escolha profissional comparando-a com as diversas variáveis e construtos 
envolvidos na OP, como é o caso da participação da família nesse processo. Adicionalmente, Pacheco, Almeida, José, Silva \& Lopes (2017) afirmam que o envolvimento dos pais na escolha profissional é importante, porém ainda ocorre de forma intuitiva. Portanto, estudos desenvolvidos nessa área podem fornecer a OP evidências empíricas para subsidiar intervenções que venham a auxiliar os pais e filhos durante a escolha profissional.

Nessa perspectiva, o estudo de Ventura \& Noronha (2014) verificou o nível preditivo do suporte familiar e dos estilos parentais percebidos para a autoeficácia para a escolha profissional em uma amostra de 142 adolescentes dos três anos do Ensino Médio de escola pública e particular. Por meio de análises de regressão as autoras verificaram que a afetividade dos membros da família e os estilos parentais, representado pela responsividade materna, foram os melhores preditores para as crenças de autoeficácia profissional, ao passo que a participação dos pais, tanto na dimensão responsividade e exigência, obteve menores níveis de contribuição para as crenças de autoeficácia profissional dos adolescentes.

Mediante o exposto considera-se a pertinência de avaliar a participação da família para a escolha profissional dos filhos conforme assinala Almeida e Melo-Silva (2011), incluindo a investigação de outras variáveis relacionadas ao momento de definição dessa escolha (Ventura \& Noronha, 2014). Conjecturam-se que varáveis inerentes à família, a saber, os estilos parentais e a congruência entre pais e filhos sobre a escolha profissional, somadas à autoeficácia para escolha profissional impactam na realização da escolha propriamente dita.

Destarte, o objetivo do presente estudo foi o de testar o potencial preditivo dos estilos parentais, da congruência entre pais e filhos e autoeficácia para escolha profissional dos filhos em relação à definição da escolha profissional de adolescentes do Ensino Médio. Os modelos testados foram: modelo 1, referente aos estilos parentais considerando os aspectos exigência e responsividade; modelo 2 , estilos parentais e a congruência entre pais e filhos sobre a escolha profissional, em suas dimensões suplementar e complementar e, por fim, o modelo 3 , que agrega aos estilos parentais e a congruência entre pais e filhos à autoeficácia para escolha profissional. Presume-se que a força preditiva para a escolha profissional aumente com o acréscimo dos construtos, sendo o modelo 3 com maior poder preditivo na decisão para a escolha profissional dos adolescentes. Estas hipóteses derivam de estudos que identificaram que o comportamento dos pais, sobretudo o apoio emocional, interferem na autoeficácia para a decisão de carreira (Metheny \& McWhirter, 2013; Raque-Bogdan, Klingaman, Martin \& Lucas, 2013; Sovet \& Metz, 2014).

\section{Método}

\section{Participantes}

Participaram deste estudo 181 estudantes matriculados no $1^{\circ}, 2^{\circ}$ e $3^{\circ}$ ano do Ensino Médio de escola pública e particular localizadas no sul de Minas Gerais, Brasil. Devido à aplicação da Escala de Exigência e Responsividade (Teixeira, Bardagi \& Gomes, 2004) adotou-se como critério de seleção a exclusão dos participantes que declararam morar apenas com o pai $(n=2)$, com a mãe $(n=29)$ e outros $(n=10)$. A amostra final contou com 140 estudantes que declararam morar com o pai e a mãe, sendo 81 mulheres $(58 \%)$ e 59 homens (42\%), com idades entre 15 e 18 anos $(M=16.14$; $D P=0.83)$. No que tange ao ano escolar, foram do $1^{\circ}$ ano $(n=6), 2^{\circ}$ ano $(n=80)$ e $3^{\circ}$ ano $(n=54)$, sendo de escola pública $(n=105)$ e particular $(n=35)$. Destes participantes $103(74 \%)$ não trabalhavam e 36 trabalhavam (26\%). Quanto à definição sobre a escolha profissional 56 alunos (40\%) declararam ter uma opção, 37 (26.43\%) apontaram para duas opções, $25(17.86 \%)$ para três ou mais e $22(15.71 \%)$ alegaram não ter uma opção definida. 


\section{Instrumentos}

\section{Questionário Sociodemográfico}

Este questionário foi elaborado para coletar os dados de identificação dos participantes, a saber, o sexo, idade, ano escolar e tipo de escola (pública ou particular). Ademais, foram solicitadas informações a respeito de com quem os estudantes moravam (apenas com o pai, com a mãe, com ambos e outros), se estavam trabalhando e sobre a definição de escolha profissional, variável abordada no presente estudo, com opções de resposta variando entre "sim, uma opção" = 1, "duas opções" = 2, "três opções ou mais" = 3, até "não ter uma opção definida" $=4$. Para fins da presente pesquisa, essas variáveis foram categorizadas para representar um continuum de definição-indefinição quanto à escolha profissional, de modo que menores pontuações indicam escolhas profissionais mais definidas e maiores pontuações, escolhas menos definidas.

Escala de Congruência entre Pais e Filhos sobre a Escolha Profissional (ECPF-EP - versão adaptada da The Adolescent-Parent Career Congruence Scale, de Sawitri et al., 2012, por Pereira, 2016) constituída por 12 itens, sendo que os respondentes devem indicar a sua percepção acerca das atitudes de seus pais sobre o processo de escolha profissional. Os itens da escala representam dois fatores de congruência: a complementar e a suplementar. O instrumento em sua versão adaptada apresentou bons índices de consistência interna (coeficientes alfa) em uma amostra de 292 alunos do Ensino Médio, sendo o fator congruência complementar com $\alpha=0.85$, o fator congruência suplementar, $\alpha=0.81$ e a ECPF-EP geral, $\alpha=0.89$ (Pereira, 2016).

Escala de Responsividade e Exigência Parental (EREP) desenvolvida por Teixeira et al. (2004), com base na Escala de Estilos Parentais (Costa, Teixeira \& Gomes, 2000). A EREP contém 24 itens, sendo 12 itens referentes à exigência e 12 referentes à responsividade, totalizando dois fatores.
O examinando é orientado a responder a EREP duas vezes, considerando a responsividade e exigência paterna e materna. Os índices de consistência interna (coeficiente alfa) foram entre $\alpha=0.78 \mathrm{e}$ $\alpha=0.93$ para os fatores de exigência e responsividade, respectivamente (Teixeira et al., 2004).

Escala de Autoeficácia para Escolha Profissional (EAE-EP, Ambiel \& Noronha, 2014), é composta por 47 itens, dividida em quatro fatores, a saber, a autoavaliação, coleta de informações ocupacionais, busca de informações profissionais práticas e planejamento de futuro. No que se refere aos estudos psicométricos com a EAE-EP, a consistência interna medida pelo coeficiente alfa apontou para o fator autoavaliação, $\alpha=0.88$, coleta de informações ocupacionais e busca de informações profissionais práticas, $\alpha=0.83$, planejamento de futuro, $\alpha=0.79$ e, a escala geral, $\alpha=0.94$. As correlações entre os fatores apresentaram-se positivas e de magnitude moderada, variando de $r=0.60$ a $r=0.63, \operatorname{com} p<0.001$.

\section{Procedimentos de coleta de dados}

A presente pesquisa seguiu todos os procedimentos éticos previstos na Resolução CNS 510/2016 do Conselho Nacional de Saúde, que regulamenta as pesquisas com seres humanos no Brasil ( $\mathrm{n}^{\mathrm{o}}$ do CAAE: 48682015.7.0000.551). Após a autorização da escola, dos responsáveis pelos alunos e dos alunos próprios alunos, via assinatura, respectivamente, dos Termos de Consentimento e Assentimento Livre e Esclarecido, foi aplicado o Questionário Sociodemográfico, a Escala de Congruência entre Pais e Filhos (ECPF-EP), a Escala de Exigência e Responsividade Parentais (EREP) e, por último, a Escala de Autoeficácia para Escolha Profissional (EAE-EP). A aplicação foi feita em sala de aula, de forma coletiva, durante o período escolar regular. O tempo total de aplicação dos instrumentos foi de 40 minutos. 


\section{Procedimentos de análise dos dados}

As análises estatísticas dos dados foram realizadas por meio por meio do software Statistical Package for the Social Sciences (SPSS), versão 22.0. Analisaram-se as estatísticas descritivas com o objetivo de caracterização da amostra e dos instrumentos (média e desvio padrão). Além disso, foi realizada a análise de regressão múltipla, com método Hierárquica, e o índice de confiabilidade alfa dos fatores das três escalas aplicadas. Interpretou-se as correlações dos fatores com base em Dancey e Reidy (2013), que consideram que valores de $r$ na casa de 0 são nulas; entre $0.10 \mathrm{e}$ 0.39 são fracos; ente 0.40 e 0.69 são moderados; entre 0.70 e 0.90 são fortes; e valores acima de 0.90 representam correlações perfeitas.

\section{Resultados}

A princípio, foi analisada a média e o desvio padrão dos fatores das escalas, sendo estas a Escala de Congruência entre Pais e Filhos (ECPF-EP), a Escala de Exigência e Responsividade Parentais (EREP) e a Escala de Autoeficácia para Escolha coeficiente alfa. A Tabela 1 apresenta os resultados obtidos.

De maneira geral, nota-se que todos os índices de confiabilidade evidenciaram boa consistência interna dos fatores $(\alpha=0.71$ a $\alpha=0.92)$. O fator congruência complementar apresentou correlações moderadas com a congruência suplementar, responsividade materna e responsividade paterna $(r=0.65$ a $r=0.45)$. Em relação ao fator congruência suplementar obteve-se correlações moderadas com os fatores responsividade materna e responsividade paterna ( $r=0.40$ e $r=0.46)$. Os fatores exigência materna e exigência paterna detiveram correlação moderada ( $r=0.53)$, assim como os fatores responsividade materna e responsividade paterna $(r=0.58)$, e os fatores exigência paterna e responsividade paterna $(r=0.48)$. Em relação a Escala de Autoeficácia para Escolha Profissional, todos os fatores foram correlacionados entre si, apresentando correlações moderadas $(r=0.45$ a $r=0.60)$

Tabela 1.

Descritivas e correlações das variáveis utilizadas

\begin{tabular}{|c|c|c|c|c|c|c|c|c|c|c|c|c|}
\hline & $M$ & $D P$ & 1 & 2 & 3 & 4 & 5 & 6 & 7 & 8 & 9 & 10 \\
\hline 1.Congruência complementar & 3.47 & 0.87 & 0.84 & & & & & & & & & \\
\hline 2.Congruência suplementar & 2.94 & 1.04 & 0.65 & 0.82 & & & & & & & & \\
\hline 3.Estilos Parentais (exigência materna) & 3.17 & 0.57 & 0.28 & 0.30 & 0.78 & & & & & & & \\
\hline $\begin{array}{l}\text { 4.Estilos Parentais (responsividade } \\
\text { materna) }\end{array}$ & 3.12 & 0.82 & 0.53 & 0.40 & 0.35 & 0.91 & & & & & & \\
\hline 5.Estilos Parentais (exigência paterna) & 2.89 & 0.73 & 0.19 & 0.22 & 0.53 & 0.18 & 0.84 & & & & & \\
\hline $\begin{array}{l}\text { 6.Estilos Parentais (responsividade } \\
\text { paterna) }\end{array}$ & 2.69 & 0.95 & 0.45 & 0.46 & 0.25 & 0.58 & 0.48 & 0.92 & & & & \\
\hline 7.Autoeficácia para autoavaliação & 3.19 & 0.49 & 0.30 & 0.24 & 0.15 & 0.08 & 0.09 & 0.07 & 0.85 & & & \\
\hline 8.Autoeficácia info. Ocupacionais & 3.09 & 0.58 & 0.21 & 0.15 & 0.13 & 0.09 & 0.12 & 0.00 & 0.54 & 0.82 & & \\
\hline 9.Autoeficácia busca info. Práticas & 2.78 & 0.63 & 0.15 & 0.13 & 0.11 & 0.10 & -0.16 & -0.25 & 0.48 & 0.60 & 0.84 & \\
\hline 10.Autoeficácia planej. Futuro & 3.27 & 0.52 & 0.23 & 0.11 & 0.08 & 0.08 & 0.08 & 0.09 & 0.45 & 0.56 & 0.50 & 0.71 \\
\hline
\end{tabular}

Nota. As correlações marcadas em negrito são significativas para $p<0,05$. Na diagonal estão as confiabilidades dos fatores medida pelo alfa. 
Na Tabela 2 encontram-se os resultados da análise de regressão linear hierárquica entre os fatores da Escala de Congruência, da Escala de Estilos Parentais e da Escala de Autoeficácia para Escolha Profissional, tendo como variável dependente a resposta dos estudantes sobre a definição quanto sua escolha profissional. Importante relembrar que maiores escores na variável de definição quanto escolha indica, de fato, indefinição, já que sugere que o adolescente considera várias possibilidades de cursos ou profissões ou que está indeciso a respeito.

Tabela 2.

Análise de Regressão Linear Hierárquica

\begin{tabular}{|c|c|c|c|c|}
\hline Modelo & VIs & $\beta$ & $t$ & $p$ \\
\hline \multirow{3}{*}{1} & Constante & & 3.318 & 0.001 \\
\hline & $\begin{array}{l}\text { Responsividade ma- } \\
\text { terna }\end{array}$ & 0.21 & 2.331 & 0.021 \\
\hline & $R^{2}=0.04$ & & & \\
\hline \multirow{4}{*}{2} & Constante & & 5.033 & $<0.001$ \\
\hline & $\begin{array}{l}\text { Responsividade ma- } \\
\text { terna }\end{array}$ & 0.41 & 4.072 & $<0.001$ \\
\hline & $\begin{array}{l}\text { Congruência Comple- } \\
\text { mentar }\end{array}$ & -0.38 & -3.811 & $<0.001$ \\
\hline & $R^{2}=0.13$ & & & \\
\hline \multirow{5}{*}{3} & Constante & & 6.239 & $<0.001$ \\
\hline & $\begin{array}{l}\text { Responsividade ma- } \\
\text { terna }\end{array}$ & 0.41 & 4.365 & $<0.001$ \\
\hline & $\begin{array}{l}\text { Congruência Comple- } \\
\text { mentar }\end{array}$ & -0.34 & -3.591 & $<0.001$ \\
\hline & $\begin{array}{l}\text { Busca de Informações } \\
\text { Profissionais Práticas }\end{array}$ & -0.28 & -3.462 & 0.001 \\
\hline & $R^{2}=0.21$ & & & \\
\hline
\end{tabular}

Nota. $1: F(1.118)=5.432 ; p=0.021 ; 2: F(2.117)=10.289$, $p<0.001 ; 3: F(3.116)=11.497, p<0.001$.

No primeiro modelo foram inseridos os fatores da EREP (responsividade e exigência materna e paterna), sendo que o fator responsividade materna foi o único preditor significativo que explicou $4 \%$ da variação na variável dependente decisão para escolha profissional $(F[1.118]=5.432 ; p=0.021)$. De maneira específica, nota-se que esse fator foi um preditor significativo, com um coeficiente beta padronizado positivo de 0.21 . No segundo modelo, foram inseridas a EREP (pai e mãe) e a ECPF-EP. Com essa inserção, os fatores relativos à responsividade materna e a congruência complementar apresentaram-se como significativos e somaram $13 \%$ da variância explicada $(F[2.117]=$ 10.289 ; $p<0.001)$, sendo ambos os fatores preditores da variável decisão para escolha profissional, com coeficientes beta padronizados de $\beta=0.40 \mathrm{e}$ $\beta=-0.38$.

Por fim, no terceiro modelo, inseriu-se EREP (pai e mãe), a ECPF-EP e a EAE-EP. Como o esperado, percebe-se um acréscimo na porcentagem de variação explicada, na qual os fatores de cada escala, representados pela responsividade materna, congruência complementar e autoeficácia na busca de informações profissionais práticas, explicaram em conjunto $21 \%$ da variável dependente definição para escolha profissional $(F[3.116]=11.497$; $p<0.001)$. Neste modelo os coeficientes beta padronizados também foram preditores significativos, variando de $\beta=-0.29$ a $\beta=0.42$.

\section{Discussão}

Ao explorar a contribuição de cada um dos fatores constituintes dos três modelos testados, é evidenciada nos estilos parentais a participação materna, no aspecto responsividade, como preditor na decisão para a escolha profissional dos filhos. Neste caso, a responsividade materna favorece com que o adolescente apresente mais de uma opção de carreira, o que representa maior indecisão em relação à escolha profissional. Presume-se que a interferência da responsividade materna nesse processo de escolha esteja associada aos comportamentos que a caracterizam, com destaque para a compreensão, o apoio emocional e o diálogo entre mães e filhos, auxiliares no desenvolvimento da autonomia e autoafirmação do adolescente e, que 
podem favorecer com que este amplie as possibilidades de carreira a ser escolhida.

Nesse sentido, Raque-Bogdan et al. (2013) identificaram que o suporte parental dos pais corrobora a percepção de autoeficácia dos filhos para o enfrentamento das adversidades, seja na carreira ou nos estudos. Particularmente o apoio emocional materno contribui para a manutenção da autoestima e do bem-estar (Boudreault-Bouchard et al., 2013), o que pode estar relacionado com a diminuição do sofrimento psíquico no processo de escolha profissional.

Verificou-se, também, o potencial preditivo da congruência complementar, somada a responsividade materna nos modelos 2 e 3 . No entanto, este aspecto se correlacionou de forma negativa com a escolha profissional. Isto indica que ao contrário da responsividade materna, a congruência complementar pode favorecer a escolha profissional, em virtude dos adolescentes que indicaram este tipo de relação com os seus pais apresentarem menor número de opções de escolha, o que confere maior clareza na tomada de decisão. Ao comparar os resultados obtidos no presente estudo com o de pesquisas que também buscaram a investigação da congruência entre pais e filhos para escolha profissional, destaca-se, mais uma vez, o estudo de Sawitri et al. (2012) com adolescentes indonésios do Ensino Médio. Os resultados desse estudo apontaram para a associação positiva entre a congruência complementar e o suporte parental para escolha de profissional, as expectativas dos pais em relação à escolha acadêmica e a satisfação de vida. Em outro estudo Sawitri e Creed (2015), também com alunos indonésios do Ensino Médio, identificaram o efeito moderador da congruência entre pais e filhos para a escolha profissional e a motivação (perspectiva da teoria das metas de realização), sendo significativa para a meta domínio (caracterizada pelo aluno orientado para os resultados) e os interesses profissionais.

O último construto que se somou ao potencial preditivo no modelo 3 para a definição da escolha profissional foi a autoeficácia para busca de informações profissionais práticas. Apesar da menor contribuição, verificada pela análise de regressão, essa dimensão é considerada um importante elemento para o processo de decisão para escolha profissional, por se constituir de crenças que favorecem o adolescente na obtenção de informações sobre a profissão a ser seguida, mercado de trabalho, dentre outros, devido às relações interpessoais com pessoas próximas ou facilmente acessíveis. Estas características se associam, ainda, com a aprendizagem ocorrida por meio dos modelos apresentados nas relações estabelecidas, o que resulta na aprendizagem profissional vicária (Ambiel \& Noronha, 2014).

Acrescenta-se que os adolescentes avaliados pontuaram escores marginalmente acima da média em autoeficácia para busca de informações profissionais práticas. Esse resultado sugere uma oscilação nessa dimensão acrescida de certa indecisão a autoavaliação do quanto esses adolescentes acreditam serem capazes para realizar a escolha profissional. Nesses casos, verifica-se a necessidade de implementação de práticas interventivas no sentido de trabalhar com as crenças de autoeficácia (Ambiel \& Noronha, 2014). Portanto, outro ponto importante a ser destacado, até mesmo anteriormente ao processo de elaboração e aplicação de intervenções em adolescentes em fase de decisão de escolha profissional, é a inclusão da autoeficácia para escolha profissional no processo de avaliação incluso na oP por agregar ferramentas que viabilizam a compreensão e o planejamento dessas intervenções, de modo a potencializá-las, visto que esse construto se mostrou como um preditor para a decisão da escolha profissional na amostra avaliada (Ambiel \& Noronha, 2011, 2012).

Com base nos resultados deste estudo, considera-se que modelo 3 se apresentou como melhor preditor para a decisão profissional. Ainda que a responsividade materna não favoreça a decisão vocacional dos filhos, por ampliar a gama de opções no momento de escolha, a congruência entre pais 
e filhos (dimensão complementar) e a autoeficácia para escolha profissional (busca de informação pessoal prática) possibilitam com que o adolescente consiga superar a indecisão e consiga definir uma profissão. Conjectura-se que o aspecto complementar favoreça com que os pais auxiliem seus filhos a se organizarem para tomar uma decisão, no sentido de estabelecer metas e explorar o leque de opções que possa surgir no momento de escolha. Aliado a este comportamento dos pais, a busca de informação pessoal prática conduz o aluno a procurar entre as pessoas de seu convívio as informações que o auxiliem na tomada de decisão.

Entretanto, deve-se sublinhar que a responsividade materna, ao predizer uma maior indefinição quanto às escolhas profissionais, pode relacionar-se a um sentimento de acolhimento por parte do adolescente. Embora a indefinição possa levá-lo ao desconforto por ainda não ter se definido quanto à sua profissão, percebe nas atitudes de compreensão e apoio emocional das mães, a empatia necessária para que o adolescente possa se engajar em tarefas de busca de informação e desenvolver crenças favoráveis quanto à escolha profissional.

A partir dos resultados do presente estudo, que reforçam os achados de estudos anteriores acerca da importância da família na escolha profissional dos filhos, por estarem também relacionadas com outras variáveis importantes para o processo de decisão, como é o caso da autoeficácia (Magalhães et al., 2012; Silva et al., 2016; Ventura \& Noronha, 2014) e da congruência entre pais e filhos (Sawitri et al., 2012) destaca-se a relevância na continuidade de estudos com essa temática. Segundo Almeida \& Melo-Silva (2011), além da perspectiva dos filhos sobre seus pais, se faz necessária a utilização do conhecimento acumulado desses estudos para preencher a lacuna existente entre a teoria e a prática. Nesse sentido, a proposta é a de utilizar os resultados de pesquisas com essa temática para elaborar e aplicar intervenções em OP com os pais, objetivando atuar nos aspectos relacionados às mudanças ocorridas na atualidade (incluindo as diferenças entre gerações), no mercado de trabalho e nas relações familiares. Supõe-se que esse tipo de atuação favoreça com que os pais se tornem agentes facilitadores para a decisão da escolha profissional dos filhos, antevendo que quanto mais bem preparados para isso, melhor se sairão no processo de construção de carreira.

Entende-se como limitações deste estudo a representação da família de maneira tradicional, onde o núcleo familiar é composto por pai e mãe, pois atualmente a concepção de família é abrangente e com diferentes combinações de representantes, ainda sendo um conceito em constante mutação e manutenção. Apesar de reportar um recorte importante da população, a amostra reduzida não permite generalização e inferência dos dados e ainda nota-se que os participantes são predominantemente do ensino público, o que pode gerar vieses e diferenciação de acordo com fatores econômi$\cos$, culturais e sociais. Por fim, sugerem-se futuras pesquisas, que sanem os problemas amostrais apresentados anteriormente, podendo acrescentar outras variáveis como preditoras da escolha profissional como, por exemplo, o autoconceito e o suporte familiar, conferindo a continuidade dos estudos envolvendo aspectos inerentes à família no processo de decisão de escolha profissional dos filhos.

\section{Referências}

Aguiar, F. H. R., \& Conceição, M. I. G. (2012). Análise da produção científica em orientação profissional: tendências e velhos problemas. Psico-USF, 17(1), 97-107. Recuperado de http:// www.redalyc.org/pdf/4010/401036088011.pdf

Almeida, M. E. G. G., \& Pinho, L. V. (2008). Adolescência, família e escolhas: implicações na Orientação Profissional. Psicologia Clínica, 20(2), 173-184. Recuperado de http://www. scielo.br/pdf/pc/v20n2/a13v20n2

Almeida, F. H. D., \& Melo-Silva, L. L. (2011). Influência dos pais no processo de escolha 
profissional dos filhos: uma revisão da literatura. Psico-USF (Impresso), 16(1), 75-85. Recuperado de http://www.scielo.br/pdf/pusf/v16n1/ a09v16n1.pdf

Ambiel, R. A., de Campos, M. I., \& Campos, P. P T. V. Z. (2017). Análise da Produção Científica Brasileira em Orientação Profissional: Um Convite a Novos Rumos. Psico-USF, 22(1), 133-145. Doi. 10.1590/1413-82712017220112

Ambiel, R. A., \& Hernández, D. N. (2016). Relações entre autoeficácia para escolha profissional, exploração e indecisão vocacional. Revista Brasileira de Orientação Profissional, 17(1), 67-75. Recuperado de http://pepsic.bvsalud. org/pdf/rbop/v17n1/08.pdf

Ambiel, R. A. M., \& Noronha, A. P. P. (2011). Construção dos itens da Escala de Autoeficácia para Escolha Profissional. Psico-USF, 16(1), 2332. Recuperado de http://www.redalyc.org/ pdf/4010/401036084004.pdf

Ambiel, R. A., \& Noronha, A. P. P. (2012). Autoeficácia para escolha profissional: teoria, pesquisas e avaliação. Psicologia em Pesquisa, 6(2), 171178. Doi:10.5327/Z1982-12472012000200010

Ambiel, R. A. M., \& Noronha A. P. P. (2014). Escala de autoefcácia para escolha profissional (EAE-EP): manual técnico. São Paulo: Casa do Psicólogo.

Bandura, A. (1997). Self-efficacy: The exercise of control. New York: W. H. Freeman and Company.

Barros, M. V. C., Noronha, A. P. P., \& Ambiel, R. A. M. (2015). Afetos, interesses profissionais e personalidade em alunos do ensino médio. Revista Brasileira de Orientação Profissional, 16(2), 161-171. Recuperado de http://pepsic. bvsalud.org/pdf/rbop/v16n2/07.pdf

Boudreault-Bouchard, A. M., Dion, J., Hains, J., Vandermeerschen, J., Laberge, L., \& Perron, M. (2013). Impact of parental emotional support and coercive control on adolescents' self-esteem and psychological distress: Results of a four-year longitudinal study. Journal of
Adolescence, 36(4), 695-704. Doi: 10.1016/j. adolescence.2013.05.002

Costa, F. T., Teixeira, M. A. P., \& Gomes, W. B. (2000). Responsividade e exigência: duas escalas para avaliar estilos parentais. Psicologia: Reflexão e Crítica, 13(3), 465-473. Recuperado de http://www.scielo.br/pdf/prc/v13n3/ v13n3a14

Dancey, C. P. \& Reidy, J. (2013). Estatística sem matemática para psicólogos. São Paulo: Editora Penso.

Duarte, M. E. (2000). Da orientação profissional à psicologia da carreira: novos desafios. Oroganizações \& Sociedade, 6(17), 129-135. Doi: 10.1590/S1984-92302000000100010

Faria, R. R., Weber, L. N. D., \& Ton, C. T. (2012). $\mathrm{O}$ estresse entre vestibulandos e suas relações com a família e a escolha profissional. Psicologia Argumento. 30(68), 43- 52. Recuperado de http://132.248.9.34/hevila/Psicologiaargumento/2012/vol30/no68/4.pdf

Hackett, G., \& Betz, N. E. (1981). A self-efficacy approach to the career development of women. Journal of vocational behavior, 18(3), 326-339. Doi: 10.1016/0001-8791(81)90019-1

Kristof, A. L. (1996). Person-organization fit: An integrative review of its conceptualizations, measurement, and implications. Personnel Psychology, 49(1), 1-49 Doi: 10.1111/j.17446570.1996.tb01790.x

Lamas, K. C. A. (2017). Conceito e relevância dos interesses profissionais no desenvolvimento de carreira: estudo teórico. Temas em Psicologia, 25(2), 703-717. Doi: 10.9788/TP2017.2-16Pt

Leung, S. A., Hou, Z. J., Gati, I., \& Li, X. (2011). Effects of parental expectations and cultural-values orientation on career decision-making difficulties of Chinese university students. Journal of Vocational Behavior, 78(1), 11-20. Doi: 10.1016/j.jvb.2010.08.004

Lent, R., \& Brown, S. D. (2006). On conceptualizing and assessing social cognitive constructs 
in career research: a measurement guide. Journal of Career Assessment, 14(1), 12-35. Doi: $10.1177 / 1069072705281364$

Lent, R., Brown, S. D., \& Hackett, G. (1994). Toward a unifying social cognitive theory of career and academic interest, choice and performance. Journal of Vocational Behavior, 45(1), 79-122. Doi: 10.1006/jvbe.1994.1027

Maccoby, E. \& Martin, J. (1983). Socialization in the context of the family: Parent-childinteraction. In P. H. Mussen, \& E. Hetherington (Eds.), Handbook of child psychology: Socialization, personality and social development (pp. 1-101). New York: Wiley.

Magalhães, M. O., Alvarenga, P., \& Teixeira, M. A. P. (2012). Relação entre estilos parentais, instabilidade de metas e indecisão vocacional em adolescentes. Revista Brasileira de Orientação Profissional, 1(13), 15-25. Recuperado de http: //pepsic.bvsalud.org/pdf/rbop/v13n1/04.pdf

Metheny, J., \& Mcwhirter, E. H. (2013). Contributions of social status and family support to college students' career decision self-efficacy and outcome expectations. Journal of Career Assessment, 21(3), 378-394. Doi: 10.1177/1069072712475164

Mitran, P. C., \& Pârvu, I. (2017). Organization of the counseling and vocational guidance centers within pre-university education. Economics, Management and Financial Markets, 12(2), 105. Recuperado de http: e0bddaead059774a741d8f8356133e08pdf

Nepomuceno, R. F., \& Witter, G. P. (2010). Influencia da família na decisão profissional: opinião de adolescentes. Revista Semestral da Associação Brasileira de Psicologia Escolar e Educacional, 14(1), 15-22. Recuperado de http://www. scielo.br/pdf/pee/v14n1/v14n1a02

Oliveira, C. T., Santos, A. S., \& Dias, A. C. G. (2016). Expectativas de universitários sobre a universidade: sugestões para facilitar a adaptação acadêmica. Revista Brasileira de Orientação
Profissional, 17(1), 43-53. Recuperado de http://pepsic.bvsalud.org/pdf/rbop/v17n1/06.pdf Oliveira, M. C., Silva, B. R., Garcia, R. G., Melo-Silva, L. L., \& Teixeira, M. A. P. (2014). Escala de autoeficácia noaconselhamento de carreira: adaptação e evidências de validade. Avaliação Psicológica, 13(3), 371-384. Recuperado de http://pepsic.bvsalud.org/pdf/avp/ v13n3/v13n3a09.pdf

Pacheco, M. M. D. R., Almeida, R. D. S., José, M. A. M., Silva, J. E. D., \& Lopes, C. D. S. (2017). $\mathrm{O}$ adolescente e a escolha profissional: um processo de aprendizagem para os pais. Educação, Cultura e Comunicação, 8(15). 85-100. Recuperado de http://www.fatea.br/seer/index.php/ eccom/article/viewFile/1709/1258

Pazzim, T. A., \& Marin, A. (2016). Programas de preparação para aposentadoria: revisão sistemática da literatura nacional. Revista Brasileira de Orientação Profissional, 17(1), 91-101. Recuperado de http://pepsic.bvsalud.org/pdf/ rbop/v17n1/10.pdf

Pereira, E. C. (2016). Escala de congruência entre pais e filhos sobre a escolha profissional: adaptação e propriedades psicométricas. (Dissertação de Mestrado, Universidade São Francisco, Itatiba). Recuperado de http://www.usf.edu.br/galeria/ getImage/385/5970590668110688.pdf

Pereira, A. A. S., Couto, V. V. D., \& Scorsolini-Comin, F. (2015). Motivações de idosos para participação no programa Universidade Aberta à Terceira Idade. Revista Brasileira de Orientação Profissional, 16(2), 207-217. Recuperado de http: //pepsic.bvsalud.org/pdf/rbop/v16n2/11.pdf

Perry, J. C., \& Shannon, L. (2017). How vocational psychologists can make a difference in $\mathrm{K}-12$ education. International Journal for Educational and Vocational Guidance, 17(1), 97-115. Doi:10.1007/s10775-016-9335-9

Pinto, J. C., \& Pinto, H. R. (2016). Projetos de vida em situações de vulnerabilidade social: uma formação para técnicos. Revista Brasileira de 
Orientação Profissional, 17(2), 163-174. Recuperado de http://pepsic.bvsalud.org/pdf/rbop/ v17n2/05.pdf

Prisco, A. P. K., Martins, C. R., \& Nunes, M. F. O. (2013). Estudos sobre autoeficácia aplicada ao desenvolvimento de carreira no Brasil: uma revisão. Revista Brasileira de Orientação Profissional, 14(1), 111-118. Recuperado de http:// pepsic.bvsalud.org/pdf/rbop/v14n1/11.pdf

Raque-Bogdan, T. L., Klingaman, E. A., Martin, H. M., \& Lucas, M. S. (2013). Career-related parent support and career barriers: An investigation of contextual variables. The $\mathrm{Ca}$ reer Development Quarterly, 61(4), 339-353. Doi: 10.1002/j.2161-0045.2013.00060.x

Sawitri, D. R., Creed, P.A., \& Zimmer-Gembeck, M. J. (2012). The adolescent-parent career congruence scale: development and initial validation. Journal of Career Assessment, 21(2), 210-226. Recuperado de http://journals.sagepub.com/doi/abs/10.1177/1069072712466723

Sawitri, D. R. \& Creed, P. A. (2015). Perceived career congruence between adolescents and their parents as a moderator between goal orientation and career aspirations. Personality and Individual Differences, 81, 29-34. Doi: 10.1016/j. paid.2014.12.061

Silva, J. E., Fuzaro, C. M., \& Pacheco, M. M. D. R. (2016). A escolha profissional para adolescentes: panorama de estudos e pesquisas. Revista Magistro, 1(13).170-185. Recuperado de http://publicacoes.unigranrio.edu.br/index. php/magistro/article/view/3092/2081

Simöes, E., Gamboa, V., \& Paixão, O. (2016). Promoting parental support and vocational deve- lopment of 8th grade students. Revista Brasileira de Orientação Profissional, 17(1), 1-11. Recuperado de http://pepsic.bvsalud.org/pdf/ rbop/v17n1/02.pdf

Sovet, L. \& Metz, A. J. (2014). Parenting styles and career decision-making among French and Korean adolescents. Journal of Vocational Behavior, 84(3), 345-355. Doi: 10.1016/j. jvb.2014.02.002

Teixeira, M. A. P., Bardagi, M. P., \& Gomes, W. B. (2004). Refinamento de um instrumento para avaliar responsividade e exigência parental percebidas na adolescência. Avaliação Psicológica, 3(1), 01-12. Recuperado de http://pepsic. bvsalud.org/pdf/avp/v3n1/v3n1a01.pdf

Ventura, C. D. \& Noronha, A. P. P. (2014). Autoeficácia para escolha profissional, suporte familiar e estilos parentais em adolescentes. Avaliação Psicológica, 13(3), 317-324. Recuperado de http://pepsic.bvsalud.org/pdf/avp/v13n3/ v13n3a03.pdf

Weber, L. N. D. (2017). Relações entre práticas educativas parentais percebidas e a autoestima, sinais de depressão e ouso de substâncias por adolescentes. International Journal of Developmental and Educational Psychology. Revista INFAD de Psicología., 2(1), 157-168. Doi: 10.17060/ijodaep.2017.n1.v2.928

Weber, L. N. D., Selig, G. A., Bernardi, M. G., \& Salvador, A. P. V. (2006). Continuidade dos estilos parentais através das gerações: transmissão intergeracional de estilos parentais. Paidéia (Ribeirão Preto), 16(35), 407-414. Doi: 10.1590/S0103-863X2006000300011

\section{Recebido: 01 de novembro de 2017 fiprovado: 31 de maio de 2018}


